\title{
Inequitable interventions and paradoxical pedagogies: how mothers are 'taught' to support their children's literacy development in early childhood
}

\begin{abstract}
At a time when neo-liberal policy agenda are resulting in many public services being taken away from families with young children, this paper draws on Basil Bernstein's concepts of visible and invisible pedagogies to reveal how professionals offer 'support' to parents of young (under five years old) children in a small town in the East Midlands (England). It draws on findings from an ethnographic study which show that mothers are 'taught' to support their young children's literacy development differently depending on the way English education policy is interpreted and enacted in the places they visit. It is argued that dominant policy discourses around 'good' parenting can lead to inequitable interventions, paradoxical pedagogies and the disempowerment of some parents. The paper therefore contributes to the wider debate about more equitable ways of working with families that will be applicable across other contexts.
\end{abstract}

Key words: parents; early childhood; education policy; literacy; pedagogy; Bernstein; public services

\section{Introduction}

Using Bernstein's $(1975,1990)$ concepts of visible and invisible pedagogies, this paper aims to explore how the education policies of different UK governments (since 1997) have been enacted in various settings set up to provide support for parents of young children (under the age of 5) in a small town in the East Midlands. Until now, research has tended to either focus on the content of what parents and early years' settings do to support children's development 
and academic achievement (e.g. Desforges \& Abouchaar, 2003; Sylva, Melhuish, Sammons, Siraj-Blatchford, \& Taggart, 2004), or on evaluating the impact of particular interventions, such as family literacy programmes, on children's learning (e.g. Close, 2001; National Early Literacy Panel, 2008; Reese, Sparks and Leyva, 2010; Swain, Brooks \& Bosley, 2014). In contrast, the study reported here offers a new focus by exploring and comparing how professionals relate to parents when they offer support in different settings, and in doing so, is able to consider the possible (unintended) consequences of particular approaches. At present, governments across the world are pursuing austerity agenda that have resulted in widespread cuts to public services whilst using 'evidence' from neuroscience to assert the importance of the early years for ensuring children's future success (Gillies, 2017), thus putting more pressure on parents to provide support for their children's learning and development. However, at the same time, increasing numbers of families are getting poorer (Dorling, 2014) and the achievement gap between poorer children and their better-off peers is not reducing (DfE, 2017a). In order to ensure that all children are able to develop well in their early years so they can go on to achieve educational success, it is therefore crucial to understand how families can be supported effectively and equitably.

\section{Policy context}

Since New Labour formed their UK government in 1997, education policy has increasingly focused on 'good' parenting as a way to improve educational outcomes for children and increase social mobility. Although there has been a broad consensus between different UK governments about the importance of 'good' parenting since then, their education policies reveal different ideas about how the state should offer support to parents.

The policies of the New Labour government (1997-2010) reflected a commitment to investing in public services for the benefit of parents and their children, as well as a paternalistic stance 
that believed parents needed state help to be 'better'. A key paper - Every Child Matters (Chief Secretary to the Treasury, 2003) - identified a range of problems that were seen to be associated with poor outcomes for children. These included living in a low income family and/or disadvantaged neighbourhood, parental unemployment and poor parenting. In addition, a large development gap was identified between children from different socio-economic groups when children entered school for the first time, with children from poorer families being classed as 'behind' in their development. Support therefore became focused more sharply on the early years, and the government pledged to establish a network of Sure Start Children's Centres in areas deemed to be in the top $20 \%$ nationally for economic deprivation. The Centres would offer universal early education, childcare, health services, as well as family and parenting support. 'Getting it right' in children's earliest years came to be seen as a way to address wider social and economic problems (Moss, 2004) with 'support' no longer seen in terms of material benefits (such as the money given to families in the form of financial benefits) but as education and advice from experts who could help working-class parents to be 'better' (Edwards \& Gillies, 2004).

The Children's Plan (DCSF, 2007) and Every Parent Matters (DfES, 2007) stated that Sure Start Children's Centres were the best way of providing support, as parents could access advice from a range of professionals under one roof. The government promised an increase in Children's Centres from 1055 to 3500 by 2010 so there would be one in every community. Although all families with young children were eligible to access the services, support was to be based on local need and focused more on the families needing extra help. Ones in the most deprived areas would receive extra funding so more intensive support could be offered.

The Impact of Parental Involvement on Children's Education (DCSF, 2008) increased the focus on parents, particularly in relation to what they did at home to support their child's educational achievement. Parents, and the home environment they created, were cited as the 
most important factors in shaping children's well-being, achievements and prospects. The report drew on evidence from the Effective Provision of Pre-school Education (EPPE) study (Sylva et al., 2004) - the first major longitudinal study of the development of children aged three to seven years in England, which was later extended to following the same children through primary and secondary education too. The researchers defined the 'right' sort of home learning environment (HLE) as one that incorporated activities such as parents reading regularly to their child, library visits, playing with and teaching letters and numbers, painting, drawing, teaching nursery rhymes and singing. It was argued that if parents actively engaged in these activities they could significantly enhance their child's development.

In 2010, a Conservative/Liberal Democrat coalition came into power. The new government continued to focus on parental responsibility and early intervention, but with the view that they were key drivers for tackling poverty (DfE, 2011). In keeping with their neo-liberal ideology, they consistently argued that if children from poorer families could do well academically, then they would be able to compete in the global marketplace, achieve social mobility and economic stability. The government pledged to retain the existing network of Sure Start Children's Centres which they saw as instrumental in targeting and providing support to families that were struggling to provide the 'right' sort of HLE. The Centres' main focus would be to increase the number of parents attending parenting programmes. This represented an ideological shift from the state being responsible for supporting families, to parents being held solely responsible for their children's learning and development. Unlike their predecessors who had invested considerable sums of money into early years' services, this has been further reinforced through substantial, ongoing cuts to public services as part of the Coalition government's (2010-2017) and the subsequent Conservative government's (2017-present) 'austerity' agenda. So despite their pledge, more than 1000 Children's Centres have closed since 2009 (Gaunt, 2019) and there is now variable provision in different localities (Jupp, 2013) with any remaining parenting 
support being heavily targeted towards working-class families and communities. This approach suggests that these families fail to take responsibility for their children's development, and are therefore in need of intervention.

It was in this context that I undertook an ethnographic study to explore how support was offered to mothers of young children (under five years old) in the different settings that were available to them in a small town in the East Midlands (England). I initially sought to answer two questions: what resources did the town have to support young children's literacy development before they started school? And, how were mothers of young children using and experiencing these resources? I chose to focus on mothers, as they continue to take significant responsibility for caring for children prior to starting school.

\section{Theoretical context}

In thinking about how mothers used and experienced the town's resources, Bernstein's (1975, 1990) concepts of visible and invisible pedagogies provided a useful theoretical framework. As has already been shown, current English education policy continues to stress the importance of parents having the knowledge and skills to be able to provide the 'right' sort of HLE and support their children's learning and development in the early years. As a result, support has been increasingly targeted towards parents who have been seen as lacking the necessary knowledge and skills, and has centred on parenting programmes designed to provide them with advice and guidance from state-funded professionals. These professionals must therefore decide what knowledge and skills the parents need and how they can gain them.

Bernstein's concepts of visible and invisible pedagogies are helpful as they attempt to explain differences between what is taught (the criteria) and how it is taught (manner of transmission). 
The more implicit the manner of transmission and the more diffuse the criteria, the more invisible the pedagogy: the more specific the criteria, the more explicit the manner of their transmission, the more visible the pedagogy. $(1975$, p.6).

Where pedagogy is visible, Bernstein (1990) argues, there is an obvious hierarchical relationship between the teacher and pupils, and rules around what is to be taught (criteria) and how it is to be taught (sequencing and pace) are made explicit to the students. The teacher exercises authority over what is taught and how, and establishes herself as a transmitter of knowledge. Where pedagogy is invisible, although the teacher still exercises some control over what and how she teaches, she takes on the role of facilitator and rules and relationships are implicit.

By applying Bernstein's framework, this small-scale, in-depth study illuminates important issues in how recent education policies have been/are enacted at a local level. It raises questions that contribute to the wider debate about more equitable ways of working with families that will be applicable across other contexts.

\section{Methodology}

For a study that aimed to describe how mothers used and experienced their local resources, it was important to recognise that mothers are not a homogeneous group with the same experiences and circumstances (Cottle \& Alexander, 2014; Draper \& Duffy, 2006; Edwards \& Gillies, 2011; Gewirtz, 2001; Gillies, 2008; Richardson, 1993). Therefore I adopted an ethnographic approach so that possible complexities and contradictions could be explored and described in detail. This approach also meant spending a prolonged period of time in various settings within the town and generating a range of data. In total, I spent fifteen months observing, collecting relevant documentation, taking photographs, writing and drawing field notes, and conducting semi-structured interviews with mothers and professionals in the 
different settings. These included two Sure Start Children's Centres, the public library and two private parent-and-child classes (music and movement/sign language). The findings reported here draw mainly on the observational data which revealed what was being taught in these different settings and how. But at times I also draw on interview data that show how the professionals' views influenced what they did and how mothers viewed the support they were offered.

Ethical considerations included ensuring that, whilst observing within the different settings, the professionals and parents were not only made aware of my reason for being there, but were also happy for me to be there. Fortunately my gender and age meant that I fitted quite easily into the different settings - I was able to gain access and consent easily, and quickly built rapport with the people there. Often I would take part in the activities, such as singing and playing and, as a result, felt that my presence was neither intrusive nor unwelcome.

\section{Results and Discussion}

\section{Pedagogies in the Sure Start Children's Centres}

The two Children's Centres ran a weekly (Monday to Friday) timetable of group sessions. Although Sure Start Children's Centres were originally established to provide universal services for families until children started school, as a result of current government policy, most of the group sessions in these centres were carefully targeted towards families (specifically working-class mothers) who had been identified as 'vulnerable' and referred by other services, such as the police, midwives, health visitors and social services.

Being labelled in this way, and being referred for help, positioned the mothers as deficient. They experienced a hierarchical relationship with the professionals who were positioned as experts who decided what support the mothers needed. The professionals designed the sessions around the knowledge and skills they thought the mothers lacked, and set the pace and 
sequencing for how this would be transmitted. In this way mothers who visited the Children's Centres experienced a visible pedagogy characterised by explicit criteria, pace and sequencing controlled by professionals.

In terms of literacy development, the criteria were specific. Mothers were seen as lacking the knowledge required to ensure their children would develop well in the first two years of life. Therefore they were taught how to communicate and interact with their young children, and about the developmental milestones set out in the Statutory framework for the early years foundation stage (EYFS framework) (DfE, 2017b). Handouts made the criteria explicit by setting out the subject matter in the order in which it would be taught, and contained questions and tasks for the mothers to complete both within a session and as homework. In terms of pace and sequencing, mothers could be referred to the Children's Centres from as early as pregnancy when they would initially be taught about bonding and attachment. This was intended to help them learn how to communicate and interact well with their child from birth, and lead to increased well-being for both mother and child. Following on from this, mothers were taught about the different milestones their baby should reach and how to support them to do so successfully. Later sessions moved on to teaching them about particular aspects of their child's development such as how brains develop, how children learn, how to encourage speech and develop language, styles of parenting and how to deal with challenging behaviour.

One group was for parents who had been referred due to a health visitor identifying their two year old as not reaching the milestone for speech and language. The four-week course was designed to teach parents correct strategies for encouraging their child to talk and increase their vocabulary. This approach portrayed the parents as deficient in the knowledge they needed to support their child's speech development, and held them responsible for supporting their child to reach this milestone even if the professionals suspected the child had a specific learning difficulty. The increasing numbers of mothers and children being referred to this course 
supported a wider discourse that many parents (mothers) in the town did not know how to support their child's learning in the right ways. Professionals working in the Sure Start Children's Centres characterised many of the families they worked with as suffering from multiple problems. These included: low educational attainment; poor maternal mental health; limited socialisation which included a refusal/reluctance to take their children to private classes or playgroups; an over-reliance on screens to keep children quiet and entertained; a lack of positive interaction between parents and children; and ignorance around how children develop.

Moreover, mothers were taught not to question the judgement of the professionals. It was unusual for mothers to have the opportunity to ask questions, but if they did, professionals ensured that their, as well as other professionals', dominant positions were maintained. For example, in response to a rare question from a mother about how best to help a child with mispronunciation, she was told to wait until her child had the two year development check with the health visitor. The health visitor could then refer the mother to the four-week course if she felt it was needed, and pre-school would help if there were further concerns. In another example, a mother asked if the professionals thought her daughter would be 'ready' for school. Their response was to ask the professionals at the pre-school she attended. This may have been due to the professionals' own lack of knowledge, but by dealing with the mothers' concerns in this way, the professionals strengthened the hierarchical relationship. They were able to distance themselves from the mothers whilst also reinforcing the idea that they should defer to the superior knowledge of other professionals in relation to children's development. At the same time, mothers were unable to get immediate help with their concerns.

Another characteristic of a visible pedagogy is an emphasis on performance i.e. the extent to which the student is meeting the criteria (Bernstein, 1990). Because the performance of the mothers (in terms of what they actually did with their child at home) could only be assessed by their responses to questions asked in the sessions, professionals taught them how their child's 
learning and development related to the different areas of learning in the EYFS Framework, so the mothers themselves could monitor their children's development. To assist them with this, mothers were given a 'learning journey' to complete with photographs of their child engaging in activities related to the different areas of learning, or as evidence that they had reached a particular milestone. For mothers in one group, their baby's development was also formally tracked and kept on record, so if they were failing to meet a particular milestone extra support could be put in place. This pedagogical practice enabled the professionals to indirectly monitor how well mothers were learning the lessons they were being taught. The assessment practices could highlight where the mother was falling short if her child was failing to reach particular milestones. In this way, the professionals exercised power over how the mother was judged and what support she could and should be offered.

Visible pedagogies were further reinforced through the way the buildings were organised. Rooms were defined either as adult spaces or spaces for children which meant that mothers and children often occupied different spaces. Instruction for the mothers usually took place in the adult spaces away from the children, who were looked after in a crèche. If both adults and children occupied a child space but the children were old enough to move around independently, chairs were used to mark out a separate space for the adults, and children were encouraged to play in a different part of the room. Chairs were also arranged so the mothers faced the teachers who positioned themselves at the front of the room. These arrangements contributed to the visible pedagogy mothers encountered. Professionals' secured a more dominant position, as it was mothers, rather than children, who were made the focus of teaching.

These visible pedagogical practices allowed the professionals to set and control the agenda, placing their analysis of the mothers' needs above what the mothers might have experienced or wanted to know. The professionals were transmitters of knowledge who explained and described the interactions and behaviours they expected from the mother. Mothers had little 
control over what and how they were taught. As well as teaching them specific ways to support their children's literacy development, they were also taught to be docile recipients of knowledge. This meant that mothers who chose to attend the Children's Centres had little power over how or what they could learn or experience.

Unintended consequences of these pedagogical practices could be seen in the way mothers were reluctant to engage with what was on offer. Many of the groups suffered from low attendance figures, and those who turned up often attended irregularly or stopped attending altogether. Professionals expressed concern that they were not always able to engage the mothers whom they felt would benefit most. By employing a visible pedagogy, Children's Centre professionals may have alienated mothers who felt insulted by or antipathetic to the idea that they needed to be 'taught' a lesson. Therefore they exercised what little agency they had to disengage from the 'support' that was on offer. Evidence to support this view is anecdotal but illuminating. A mother who had just started attending a group mentioned that her friend did not want to come along because she "did not need anyone telling me how to bring up my baby". Another mother commented that one professional was too "school-mistressy" and that the sessions were like being at school. Therefore she was planning to leave the group soon.

\section{Pedagogies in the library and private parent-and-child classes}

Like Children's Centres, the current government's 'austerity' agenda have resulted in many public libraries being closed or, in some cases, taken over by community groups (often with reduced opening hours). Like libraries in other small to medium-sized towns in England, this has resulted in the public library in this study servicing not just the town population but also that of its surrounding villages. This included running free twice-weekly story and rhyme sessions for families with children up to the age of five. Unlike Children's Centres and public libraries that are state-funded services, the two private parent-and-child classes were provided 
by private individuals who charged parents a significant fee for their services. Part of this was used to cover the cost of renting space in the church buildings they operated from once a week. The classes incorporated activities that were designed to promote language and communication, and involved adults and young children interacting together in different ways. One was based around music and movement, and the other was based around using sign language with babies.

In contrast to mothers who visited the Children's Centres, mothers who chose to take their children to the library and/or private classes experienced a more invisible pedagogy based on modelling and suggestion. Mothers were not the focus. They were not separated from their children but were encouraged to interact and experience what was on offer together. Pedagogical practices, such as singing, moving and using different props were designed to engage the children and enhance their learning. Unlike the mothers who experienced a visible pedagogy, the mothers in these places were not given specific tasks to do or asked questions to check their understanding or to find out what they did at home with their child. Monitoring their or their child's performance appeared to be of little concern to the professionals.

However this does not imply an absence of criteria. Both the private classes were planned in advance according to a scheme of work that other 'teachers' running the same classes in different areas also used. Therefore the professionals still had a considerable amount of control over what happened in their sessions. Planned activities were linked to the EYFS framework where possible, and in both classes, there was a specific focus on developing children's vocabulary. The music and movement class also incorporated songs, actions and a story to help develop children's knowledge of letter sounds, listening skills, fine and gross motor skills and eye-tracking. However, in contrast to the groups at the Children's Centres, the criteria were invisible, explicitly known only by the leaders of the classes. The content, sequencing and pace of the sessions, as well as the benefits of particular activities were rarely shared with the mothers, unless they asked. Instead, the professionals worked on the assumption that mothers 
signed up for the classes because they already recognised some of the benefits for their children's learning. In addition they hoped that through taking part and having the activities modelled to them by the leader, they would pick up ideas about how to help their child's development at home. The leaders saw themselves as facilitators, rather than transmitters.

In contrast to the distancing of the professionals that could be seen in the Children's Centres, children and adults (including the leader) sat on colourful, soft mats facing inwards to make a circle. This layout positioned the leaders of the private classes on a more equal footing with their participants as nobody was elevated or separated. This also enabled a more sociable and informal relationship with the mothers. Although the classes were not full (there was a cost), the mothers and children that attended did so regularly. Mothers willingly took part in the activities, literally and figuratively 'buying into' what the private classes offered them and their children.

However, similar to the Sure Start professionals, the librarians employed a deficit discourse, asserting that many children were often left to their own devices and entertained by screens rather than interacting with others, and that their parents lacked the skills and education to know how to support their children's literacy development. But instead of trying to explicitly teach these parents how to support their children's literacy in the way the Sure Start professionals did, the librarians employed a more invisible pedagogy based on suggestion and modelling. For example, picture books were made more visible and accessible, suggesting these as the best reading materials for young children. Also, a display showed well-known, popular picture books and encouraged parents to share these books with their child (Smith, 2018). The librarians that led the story and rhyme sessions were keen to model the type of behaviours they wanted mothers to display with their children, such as joining in with action songs and nursery rhymes, listening to and interacting with stories, but they did not follow a pre-set plan each week. Instead, they chose songs and stories that they hoped would engage the 
children and their adults, sometimes asking children for song suggestions. Thus they exercised some control over what was presented to participants in these sessions, but little control over what the mothers and children actually did. Sessions were very informal with participants able to move in, out and around the area freely. In some cases, adults and children had minimal interaction, with mothers preferring to socialise and chat with other each. However the librarians were reluctant to establish a hierarchy where they took an authoritative role and insisted on mothers and children engaging in their preferred literacy practices, as they felt this might have alienated them and stopped them coming to the library altogether.

Like the private classes, children were not separated from their carers in the library. During the story and rhyme sessions, a few soft toys and cushions were scattered on the floor to encourage the children to sit, but there were no defined places to sit and everybody was scattered around with some mothers sitting in friendship groups. However due to the large number of people that usually attended, the librarian did sit on a chair above the adults and children. As the librarians very much believed it was their role to model the types of behaviours they wanted parents to engage in with their children, it was important for them to be visible even if this meant occupying a more dominant position.

\section{Conclusion}

Dominant policy discourses around 'good' parenting and the importance of 'getting things right' in children's earliest years so they can do well academically and secure their future economic success, frame particular parents as 'deficient' and lacking knowledge. By assuming that working-class people do not know, want or value the 'right' things (Lawler, 2014), they are positioned as in need of intervention. Policy is then enacted through public services in ways that reinforce the dominant discourse. This can be seen in interventions that employ a visible pedagogy based on the assumption that particular parents need to be taught how to be 'better'. 
Even if they care for and spend the same amount of time with their children, working-class mothers are assumed to lack the knowledge about how to do it 'right' so they must be taught the necessary skills (Vincent, 2000).

Similarly, a deficit discourse influenced the way support was offered to mothers who attended the Sure Start Children's Centres in this town. Working-class mothers, who experienced the visible pedagogies there, were assumed to lack the knowledge and skills needed to provide the 'right' sort of home learning environment for their children. This assumption meant they were subject to considerable control within the groups they attended, as the professionals established a clear hierarchy. Yet the visible pedagogies they experienced created a paradox. On the one hand they were 'taught' to be responsible for making sure their child reached development milestones, and about the importance of interaction and ways to encourage speech and language. On the other hand, a pedagogy of separation meant they were not able to interact with their children within the sessions. Paradoxically they were more likely to find themselves divided from their children who were handed over to professionals to look after in crèches or encouraged to play by themselves. It was clear that mothers were the focus of the teaching and therefore support was adult-orientated with little or no modelling by the professionals (as happened in the private classes and at the public library). Additionally, the professionals decided what the mothers needed to be taught about. The led to a further paradox. Rather than empowering the mothers, the nature of the intervention meant that even if they asked for specific advice, it was not forthcoming.

The issue of power in pedagogic relationships is not new. Bernstein (1990) argued that "pedagogic practices are cultural relays of the distribution of power" (p.73) and Freire (1970) showed how an oppressive pedagogy based on the teacher depositing knowledge into passive recipients gave them little scope for action beyond receiving and storing the knowledge. Students became accepting of the way things were, rather than eager to change them. This may 
help to explain why groups in the Children's Centres were poorly attended and many mothers stopped attending after a short while. By giving them little or no choice over the support they could access, it appeared that many mothers exercised the only power they had, which was to stop attending or refuse to engage in the first place. In light of this finding, another ethical consideration arises. Because a deficit discourse was well-established in the town, the professionals involved in this study believed they were providing valuable support for 'vulnerable' families. Therefore the findings must be sensitively communicated.

In contrast to how support was experienced by mothers in the Children's Centres, mothers who chose to go to private classes and/or the library experienced a more invisible, child-centred pedagogy where the focus of support was on the child and could directly benefit them. 'Good' parenting practices were modelled and mothers were encouraged to interact with their children. Furthermore, mothers were able to directly witness the benefits of particular practices for their children's development. Support was provided in ways that did not appear to discriminate between them, separate them from their children or scrutinise their parenting practices. Attendance was more regular, with the library sessions having the largest attendance, suggesting that the use of invisible pedagogies where relationships are more balanced and collaborative, are more successful at engaging parents with young children.

While it is important to re-emphasise that the findings reported here relate to a small number of settings within one town and therefore cannot claim to be representative of how support is offered in other places and contexts, important issues are raised for thinking about how government policies are enacted in other contexts. Questions should be asked about how support might be offered in ways that do not create an obvious power differential between professionals and the people they wish to help. 
In beginning to consider more equitable ways of supporting parents, it is first important to note that some studies have shown that concerns over the poor parenting practices of working-class families can be misplaced and certainly over-essentialised. For example, in their study of parenting practices, Dermott and Pomati (2016) found that the working-class parents they surveyed engaged in child-centred activities seen as markers of 'good' parenting, such as reading to their children and playing with them. Other researchers have shown that workingclass mothers make powerful emotional commitments to their children, taking on the day-today caring for children, and wanting their children to do well at school so they can escape financial hardship (Gillies, 2005, 2006; Hays, 1996). The issue at stake is not that poorer parents do not care enough but that they have less access to useful resources. Therefore, when professionals are deciding what and how support should be offered, in order to empower and involve parents that may be 'hard to reach', they could look for ways to take their perspectives into account (Swain, Brooks and Bosley, 2014) and consider what resources they would like. Close (2001) found that parent-centred approaches helped them to become more confident at supporting their children's literacy and creating the 'right' sort of home learning environment. In his evaluation of an initiative (Talk To A Literacy Learner programme) designed to bring pre-schools, schools and parents together to raise children's literacy achievement, Cairney (1996) also argued that parents and practitioners needed to feel that they were working in partnership to enhance their children's literacy learning. It is worth noting that when Sure Start Children's Centres were originally created, parents and local communities were actively involved in decision-making around the types of services they wanted and needed (Bagley \& Ackerley, 2006; Lewis, 2011). However, when responsibility for the Centres was moved from central government to local authorities in 2006, they took on the role of deciding what was needed in particular communities which led to many parents becoming disengaged and suspicious of the support that was offered (Bagley, 2011; Lewis, 2011). 
Whilst recognising that parents and professionals should work in closer partnership, it is also important to recognise that not all parents or children are the same and approaches that work well in some communities may not work in other contexts. In terms of support for children's literacy development, initiatives that incorporate practices and texts that parents are familiar with have been found to be more successful (Anderson, Anderson, Freidrich and Kim, 2010). This approach is supported by Day, Williams and Fox (2009) who reported that initiatives designed to help parents support their children's learning were most successful when they validated parents' prior knowledge and skills and were consistent with their own philosophies and approach, e.g. using role play to support early language and literacy development. Therefore, by recognising and building on parents' existing knowledge and skills, they are more likely to feel empowered to support their children's learning and development.

I would also argue that for the increasing number of poorer families (O’Brien \& Kyprianou, 2017), free, universal support is vital. In the town in this study, apart from outdoor spaces such as the park, the public library was the only place they could go with their children that was free and open to everyone.

Neo-liberal government policies that emphasise individual responsibility have led to a lack of state investment in early years' services beyond childcare, and a growing number of families living in poverty. At the same time, poorer children are not able to achieve the same academic success as their better-off peers, despite the growing numbers in early education/childcare settings for a longer time (DfE, 2017c). Therefore it is important to understand how opportunities to support young children's learning and development can be maximised. If we want to empower all parents to support their children's early development, I suggest that early years' service providers look for ways to offer support that do not discriminate between and make assumptions about users. Rather than assuming a more powerful position, professionals could focus on collaborating with mothers and fathers to design free, universal services that 
build on their, and their children's, existing knowledge and skills. In this way young children's development could be supported more directly and parents could recognise benefits for their children's learning, which they are then more likely to replicate and build on at home.

\section{References}

Anderson, J., Anderson, A., Friedrich, N., \& Kim, J. E. (2010) Taking stock of family literacy: Some contemporary perspectives. Journal of Early Childhood Literacy, 10(1), pp.3353.

Bagley, C. (2011) From Sure Start to Children's Centres: capturing the erosion of social capital. Journal of Education Policy, 26(1), pp.95-113.

Bagley, C., \& Ackerley, C. (2006) 'I am much more than just a mum'. Social capital, empowerment and Sure Start. Journal of Education Policy, 21(6), pp.717-734.

Bernstein, B. (1975) Class Pedagogies: Visible and Invisible. France: Organisation for Economic Co-operation and Development.

Bernstein, B. (1990) The Structuring of Pedagogic Discourse. London: Routledge.

Cairney, T. (1996) Developing partnerships with families in literacy learning. In S. Wolfendale \& K. Topping (Eds.), Family Involvement in Literacy: Effective Partnerships in Education. London: Cassell, pp. 131-146

Chief Secretary to the Treasury. (2003) Every Child Matters. London: HMSO

Close, R. (2001) Parental Involvement and Literacy Achievement: The Research Evidence and the Way Forward. London: National Literacy Trust 
Cottle, M., \& Alexander, E. (2014) Parent partnership and "quality" early years services: Practitioners' perspectives. European Early Childhood Education Research Journal, 22(5), pp.637-659.

Day, L., Williams, J., \& Fox, J. (2009) Supporting Parents with their Children's 'at home' Learning and Development. London: Department for Children, Schools and Families.

DCSF. (2007) The Children's Plan: Building Brighter Futures. London: Department for Children, Schools and Families.

DCSF. (2008) The Impact of Parental Involvement in Children's Education. London: Department for Children, Schools and Families.

Dermott, E., \& Pomati, M. (2016) 'Good' parenting practices: How important are poverty, education and time pressure? Sociology, 50(1), pp.125-142.

Desforges, C., \& Abouchaar, A. (2003) The Impact of Parental Involvement, Parental Support and Family Education on Pupil Achievements and Adjustment: A Literature Review. Nottingham: Department for Education and Skills.

DfE. (2011) Supporting Families in the Foundation Years. London: Department for Education. DfE. (2017a) Early Years Foundation Stage Profile Results in England. London: Department for Education.

DfE. (2017b) Statutory Framework for the Early Years Foundation Stage: Setting the Standards for Learning, Development and Care for Children from Birth to Five. London: Department for Education.

DfE. (2017c) Childcare and Early Years Survey of Parents in England 2017. London: Department for Education 
DfES. (2007) Every Parent Matters. Nottingham: Department for Education and Skills.

Dorling, D. (2014) Inequality and the 1\%. London: Verso.

Draper, L., \& Duffy, B. (2006) Working with parents. In Pugh, G. \&, Duffy, B (Eds.), Contemporary Issues in the Early Years (pp.151-161). London: Sage.

Edwards, R., \& Gillies, V. (2004) Support in parenting: Values and consensus concerning who to turn to. Journal of Social Policy, 33(4), pp.627-647.

Edwards, R., \& Gillies, V. (2011) Clients or consumers, commonplace or pioneers? Navigating the contemporary class politics of family, parenting skills and education. Ethics and Education, 6(2), pp.141-154.

Freire, P. (1970/2017) Pedagogy of the oppressed (Penguin Modern Classics version) London: Penguin Random House

Gaunt, C. (2019) Children's services in England face cash crisis, warn charities. Nursery World [online] www.nurseryworld.co.uk/nursery-world/news/1166974/childrens-services-inengland-face-cash-crisis-warn-charities

Gewirtz, S. (2001) Cloning the Blairs: New Labour's programme for the re-socialization of working-class parents. Journal of Education Policy, 16(4), pp.365-378.

Gillies, V. (2005) Meeting parent's needs? Discourses of 'support' and 'inclusion' in family policy. Critical Social Policy, 25(1), pp.70-90.

Gillies, V. (2006) Working class mothers and school life: Exploring the role of emotional capital. Gender and Education, 18(3), pp.281-293.

Gillies, V. (2008) Perspectives on parenting responsibility: Contextualizing values and practices. Journal of Law and Society, 35(1), pp.95-112. 
Gillies, V. (2017) Challenging the politics of early intervention: Who's saving children and why. Bristol: Policy Press

Hays, S. (1996) The Cultural Contradictions of Motherhood. New Haven: Yale University Press.

Jupp, E. (2013) Enacting parenting policy? The hybrid spaces of Sure Start Children's Centres. Children's Geographies, 11(2), pp.173-187.

Lawler, S. (2014) Identity: Sociological Perspectives. Cambridge: Policy Press.

Lewis, J. (2011) From Sure Start to Children's Centres: An Analysis of Policy Change in English Early Years Programmes. Journal of Social Policy, 40(1), pp.71-88.

Moss, P. (2004) Sure Start. Journal of Education Policy, 19(5), pp.631-634.

National Early Literacy Panel. (2008). Developing Early Literacy: Report of the National Early Literacy Panel. Maryland: National Institute for Literacy.

O'Brien, M., \& Kyprianou, P. (2017) Just Managing? What it Means for the Families of Austerity Britain. Cambridge: Open Book Publishers.

Reese, E., Sparks, A., \& Leyva, D. (2010). A review of parent interventions for preschool children's language and emergent literacy. Journal of Early Childhood Literacy, 10(1), pp.97117.

Richardson, D. (1993) Women, Motherhood and Childrearing. Basingstoke: Macmillan Press.

Smith, H. V. (2018) Cooking the books: What counts as literacy for young children in a public library? Literacy, 52(1), pp.31-38.

Swain, J., Brooks, G., \& Bosley, S. (2014) The benefits of family literacy provision for parents in England. Journal of Early Childhood Research, 12(1), pp.77-91. 
Sylva, K., Melhuish, E., Sammons, P., Siraj-Blatchford, I., \& Taggart, B. (2004) The Effective Provision of Pre-School Education (EPPE) Project: Findings from Pre-school to End of Key Stage 1. Nottingham: Department for Education and Skills.

Vincent, C. (2000) Including Parents? Education, Citizenship and Parental Agency. Inclusive Education. Buckingham: Open University Press. 